\title{
Spatial and temporal analysis of Iran precipitation
}

\author{
Omid Memarian Sorkhabi \\ (omidmemaryan@gmail.com) \\ Department of Geomatics Engineering, Faculty of Civil Engineering and Transportation, University of Isfahan, \\ Isfahan, Iran.
}

\begin{abstract}
:
In this study, spatial and temporal analysis of precipitation in Iran in 2019 and 2020 has been studied. The average annual precipitation in 2019 is about $345 \mathrm{~mm}$ and in $2020285 \mathrm{~mm}$. In 2019, the maximum precipitation was in the western and northwestern regions, and the minimum precipitation was in the central and eastern regions. In 2020, the maximum precipitation was in the northwestern areas and the minimum precipitation was in the central, eastern and southwestern areas. Northwestern regions of Iran have a positive precipitation difference, i.e. in 2020 it had more precipitation. The southern and western regions have a negative difference, i.e. in 2020, there was less rain.
\end{abstract}

Keywords: Precipitation, Iran, Spatial and temporal analysis, 2020

\section{Introduction}

Iran is located in the global arid region and its average precipitation is $250 \mathrm{~mm}$, so that $25 \%$ of Iran's soil is in the arid regions, $40 \%$ in the arid regions and $25 \%$ in the semi-arid regions [1]. Water resources are located in a small part of the country's area and should be transferred from these areas to two thirds of Iran's area, which is one of the water-scarce areas. Given that Iran is one of the regions that will face a water crisis in the future, by 2050 the per capita share of water per person will reach less than one thousand cubic meters. It now has about 95 large dams and 36.5 billion meters. There are 45 large irrigation and drainage networks in the country that cover the equivalent of 1.4 billion hectares of land [2]. Geodesy and satellite data can play a good role in measuring climatic parameters [3-11].

In this study, spatial and temporal analysis of precipitation in Iran in 2019 and 2020 has been studied. 


\section{Results}

Satellite data between 2019 and 2020 have been used for spatial and temporal analysis of Iranian precipitation. The average annual precipitation in 2019 is about $345 \mathrm{~mm}$ and in 2020 is $285 \mathrm{~mm}$. Figures 1 and 2 show the precipitation in Iran in 2019 and 2020. In 2019, the maximum precipitation was in the western and northwestern regions, and the minimum precipitation was in the central and eastern regions. The maximum precipitation in 2019 will reach $650 \mathrm{~mm}$.

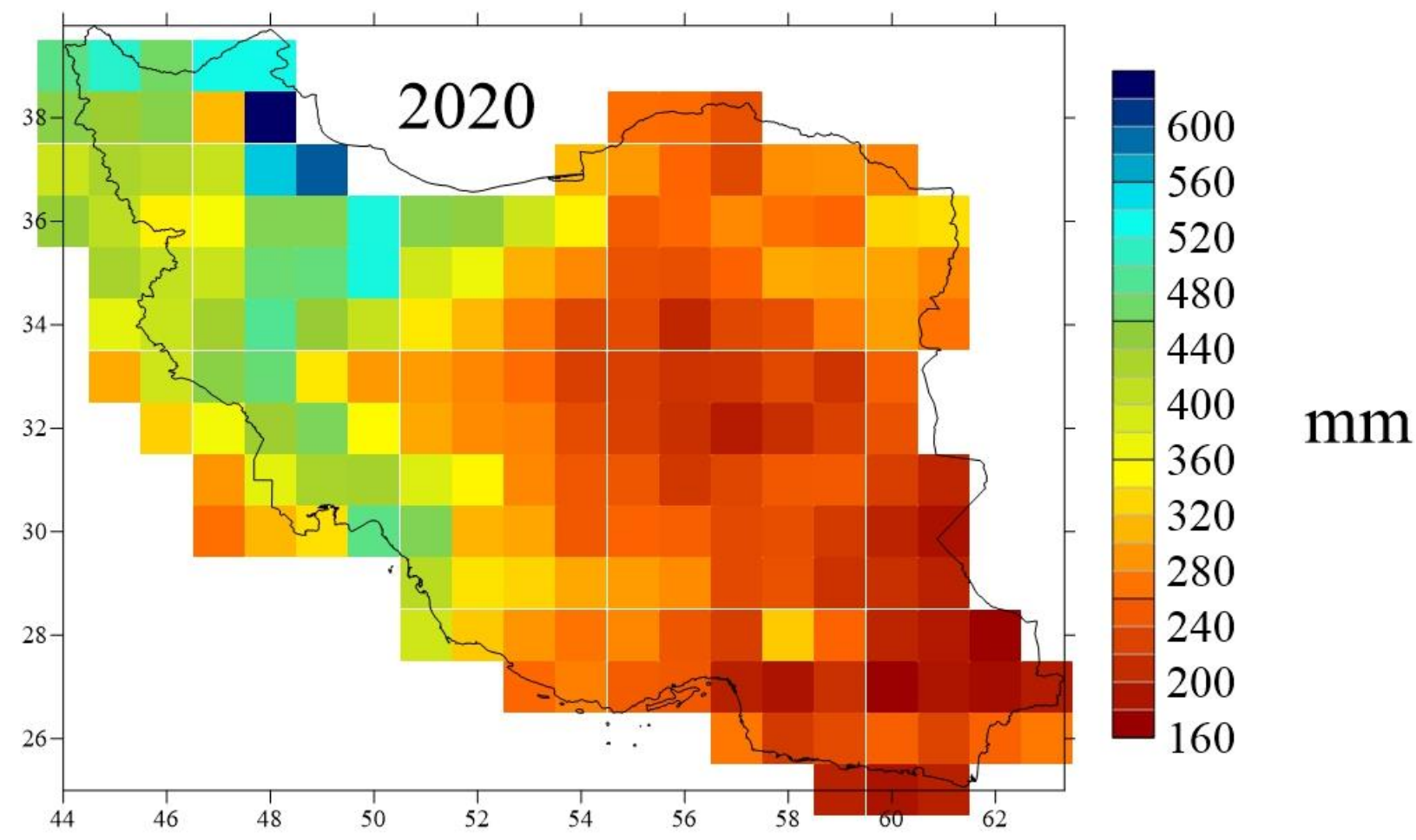

Figure 1 Precipitation in Iran in 2019

In 2020, the maximum precipitation was in the northwestern areas and the minimum precipitation was in the central, eastern and southwestern areas. The maximum precipitation in 2020 will reach $650 \mathrm{~mm}$. Compared to 2019, the precipitation has decreased in 2020. 


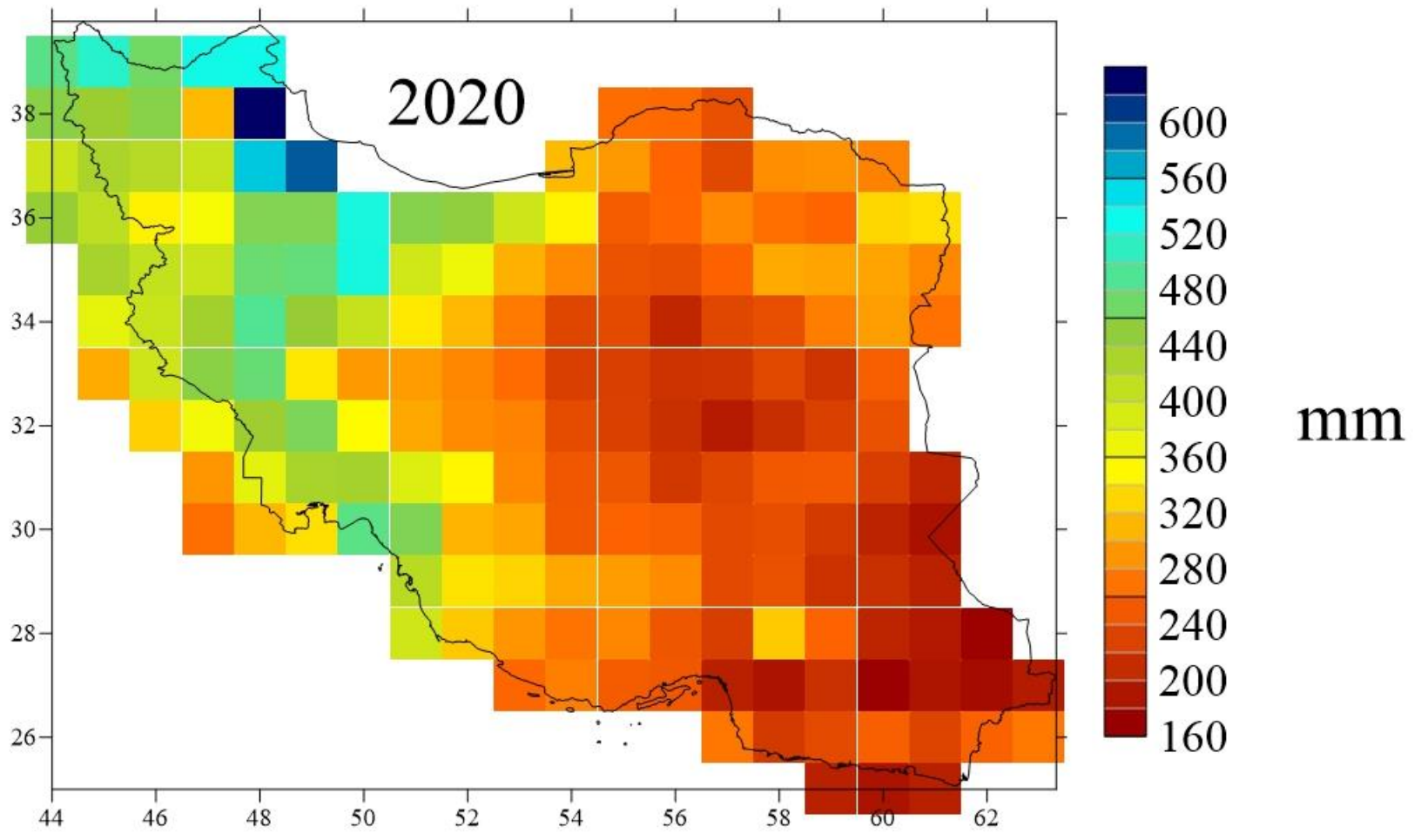

Figure 2 Precipitation in Iran in 2020

The difference in spatial and temporal precipitation of Iran in 2019 and 2020 is shown in Figure 3. Northwestern regions of Iran have a positive precipitation difference, ie in 2020 it had more precipitation. The southern and western regions have a negative difference, ie in 2020 , there was less rain. 


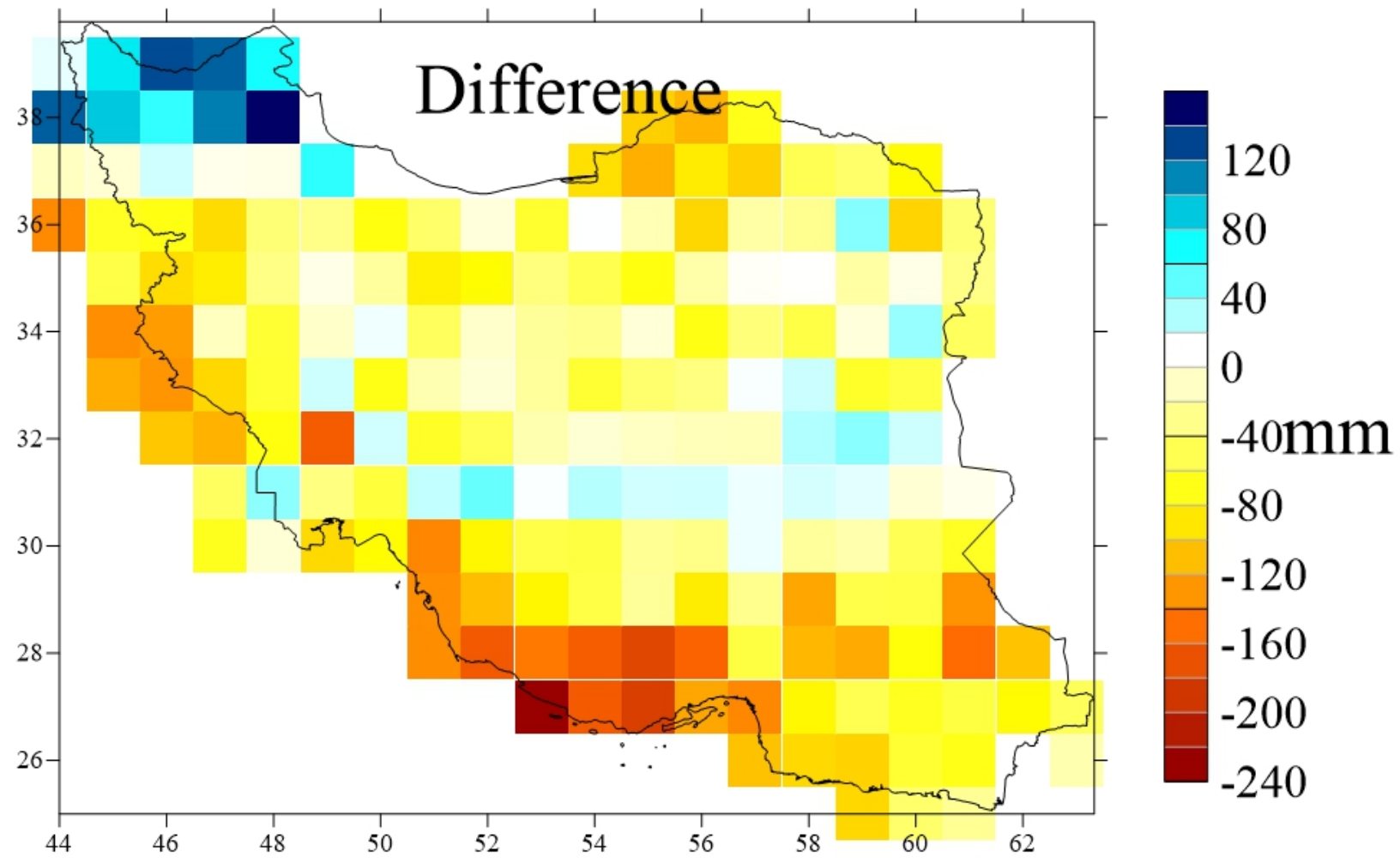

Figure 3: Spatial and temporal differences in precipitation in Iran in 2019 and 2020

\section{Conclusion}

In this study, spatial and temporal analysis of precipitation in Iran in 2019 and 2020 has been studied. The average annual precipitation in 2019 is about $345 \mathrm{~mm}$ and in $2020285 \mathrm{~mm}$. In 2019, the maximum precipitation was in the western and northwestern regions, and the minimum precipitation was in the central and eastern regions. In 2020, the maximum precipitation was in the northwestern areas and the minimum precipitation was in the central, eastern and southwestern areas. Northwestern regions of Iran have a positive precipitation difference, ie in 2020 it had more precipitation. The southern and western regions have a negative difference, ie in 2020, there was less rain. 


\section{Competing interests:}

The authors declare no competing interests.

\section{References}

[1] Ghamghami M, Bazrafshan J. Relationships between Large-Scale Climate Signals and Winter Precipitation Amounts and Patterns over Iran. Journal of Hydrologic Engineering. 2021 Mar 1;26(3):05021001.

[2] Asadi M, Khorshiddoust AM, Dadashi Roudbari AA. Assessment the spatial correlation of precipitation in Iran. Geography and Planning. 2021 Jan 20;24(74):1-1.

[3] Memarian Sorkhabi O, Asgari J, Amiri-Simkooei A. Wavelet decomposition and deep learning of altimetry waveform retracking for Lake Urmia water level survey. Marine Georesources \& Geotechnology. 2021 Mar 10:1-1

[4] Memarian Sorkhabi O. Geoid determination based on log sigmoid function of artificial neural networks:(a case study: Iran). Journal of Artificial Intelligence in Electrical Engineering. 2015 Mar 1;3(12):18-24.

[5] Sorkhabia OM, DJAMOUR Y. Wavelet Transform Analysis of Ionospheric Electron Content Changes before Large Earthquakes. Journal of Geomatics Science and Technology, 2015.

[6] Sorkhabi OM, Naderi A, Emadi R. Terrain Effect on Geoid Determination Case Study: NW Iran. Journal of Geomatics Science and Technology. 2014 Nov 10;4(2):139-48.

[7] Sorkhabi OM. Deep learning of dynamic sea-level variability to investigate the relationship with the floods in Gothenburg. 2021. DOI: 10.21203/rs.3.rs-422515/v1

[8] Memarian Sorkhabi O, Asgari J, Amiri-Simkooei A. Monitoring of Caspian Sea-level changes using deep learning-based 3D reconstruction of GRACE signal. Measurement. 2021 Apr 1;174:109004.

[9] Sorkhabia OM, Asgaria J, Amiri-Simkooeia A. Caspian Sea Level Survey with GRACE and GRACE-FO. 2020.

[10] Memarian Sorkhabi O, Djamour Y. Estimation of Geodetic Virtual Velocity Based On Back Propagation Artificial Neural Networks (Case Study: NW Iran). Journal of Geoscience. 2015 Jun 1;24(95):69-76.

[11] Memarian Sorkhabi O, Asgari J, Amiri Simkooei A. Analysis of Greenland mass changes based on GRACE four-dimensional wavelet decomposition. Remote Sensing Letters. 2021 May 4;12(5):499-509. 